\title{
Expectativas relacionadas à reinserção familiar: um estudo com adolescentes com histórico de situação de rua, familiares e educadores
}

\section{Expectations related to the family reintegration: A study with adolescents with street history, relatives and social educators}

\author{
Expectativas relacionados con la reintegración familiar: Un \\ estudio de adolescentes con histórico de situación de calle, \\ familia y educadores sociales
}

\author{
Sara Guerra Carvalho de Almeida* \\ Universidade de Fortaleza - UNIFOR, Fortaleza, Ceará, Brasil \\ Normanda Araujo de Morais** \\ Universidade de Fortaleza - UNIFOR, Fortaleza, Ceará, Brasil
}

\begin{abstract}
RESUMO
Este estudo objetivou analisar as expectativas acerca da reinserção familiar (RF) de adolescentes com histórico de situação de rua, a partir da perspectiva de três categorias de participantes (cinco adolescentes, cinco familiares e dois educadores sociais), que responderam a uma entrevista semi-estruturada um mês antes da saída dos adolescentes da instituição de acolhimento e, portanto, do seu regresso às casas de familiares. A análise de conteúdo das entrevistas mostrou que as expectativas dos adolescentes tendem a ser mais positivas que a dos seus familiares e educadores sociais. No entanto, os adolescentes descreveram-se com medo, inseguros e ansiosos para voltarem para casa. Ainda, constatou-se que os adolescentes mencionaram o desejo de reencontrar os familiares e que os familiares e educadores frisaram as dificuldades e limites do contexto (uso de drogas, falta de habitação e a violência na comunidade). As três categorias de participantes, porém, citaram a importância do programa "jovem aprendiz" para a reinserção. Conclui-se ressaltando a relevância da escuta desses três importantes atores do processo de RF, assim como da importância da prévia preparação dos adolescentes e suas famílias, de forma que a reinserção não se limite à reunificação física, mas que implique uma reunificação psicológica dos adolescentes às suas famílias e vice-versa.
\end{abstract}

Palavra-chave: reinserção familiar, institucionalização, situação de rua, adolescentes, família.

\section{ABSTRACT}

This study aimed to analyze the expectations about family (FR) reintegration of institutionalized adolescents with street history from the perspective of three categories of participants (five adolescents, five relatives and two social educators), who responded to a semi-structured interview a month 
before these adolescents' departure from the host institution and, therefore, their return to their homes and relatives'. Content analysis of interviews showed that expectations of teens tend to be more positive than those of their family and social educators. However, adolescents described themselves scared, insecure and eager to return home. Still, it was found that teens mentioned the desire to reconnect with the family and that family members and educators stressed the difficulties and limitations of context (drug use, homelessness and violence in the community). The three categories of participants, however, have cited the importance of the program "young Apprentice" for reinsertion. It is concluded that the importance of listening to these three important actors of the RF process stands out, as well as the importance of prior preparation of adolescents and their families, so that reinsertion is not bound to the physical reunification, but involves a teenagers' psychological reunification with their families and vice versa.

Keywords: family reintegration, institutionalization, street situation, adolescents, family.

\section{RESUMEN}

Este estudio tuvo como objetivo analizar las expectativas sobre la reintegración familiar (RF) de adolescentes institucionalizados con histórico de situación de calle, desde la perspectiva de tres categorías de participantes (cinco adolescentes, cinco familiares y dos educadores sociales), que respondieron a una entrevista semiestructurada un mes antes de la salida de los adolescentes de la institución para ir a vivir con sus familiares. El análisis de contenido de las entrevistas indicó que las expectativas de los adolescentes tienden a ser más positivas que las de los familiares y educadores. Sin embargo, los adolescentes se describieron con miedo, inseguros y ansiosos por volver a casa. Además, los adolescentes mencionaron el deseo de reencontrarse con su familia, mientras los familiares y educadores subrayaron las dificultades y los límites del contexto (uso de drogas, falta de vivienda y violencia en la comunidad). Los tres categorías de participantes, sin embargo, mencionaron la importancia del programa "joven aprendiz" para la reinserción. Se concluye resaltando la relevancia de la escucha de estos tres importantes actores del proceso de RF, así como de la previa preparación de los adolescentes y sus familias, de forma que la reinserción no se limite a la reunificación física, si no que implique una reintegración psicológica de los adolescentes a su familia y viceversa.

Palabra clave: reintegración familiar, institucionalización, situación de calle, adolescentes, familia.

\section{I ntrodução}

As crianças e adolescentes em situação de rua são considerados como sujeitos que usufruem do espaço da rua para a sua subsistência ou como local de moradia. Mas, para abranger toda essa situação é necessário compreender o processo de vulnerabilização anterior que predispõe a busca pela rua, seja ela para mendicância, vendas de produtos, brincadeiras e até mesmo moradia (Morais, Paludo, \& Koller, 2010; Santana, Doninelli, Frosi, \& Koller, 2004). 
De acordo com Morais, Paludo e Koller (2010), a vulnerabilidade social é entendida como o resultado negativo entre o acesso aos recursos (sejam materiais ou simbólicos) e o acesso às estruturas de oportunidades sociais, econômicas, e culturais providas pelo Estado, mercado e sociedade. Alguns desses fatores de risco também são originados no contexto familiar: pobreza, desemprego, monoparentalidade, famílias com grande número de filhos, violências (física, psicológica e/ou emocional), dependência química e morte de algum familiar importante que a criança e/ou adolescente esteja vinculado. Outros contextos também são considerados como fatores de risco, como a fragilização dos vínculos escolares, a falta de alternativas de lazer na comunidade, a insegurança e a violência. Assim, a soma dos fatores de risco contribui para a ruptura e a gradual vinculação do adolescente com a rua, sendo a ida para a rua uma alternativa de sobrevivência ao ambiente familiar e comunitário violadores.

As etapas da trajetória de vida de uma criança ou adolescente em situação de rua são produzidas por diferentes fatores, de acordo com Lucchini (2003). Dentre os fatores estão: a) modalidades de partida para a rua; b) referências e modelos identitários; c) competências simbólicas e instrumentais; d) grau de inserção e participação na vida da rua; e) movimentos entre os diferentes campos (rua, família, parentes, escola, instituição, etc.); f) necessidades e motivações; g) modalidades de saída da rua; e, por fim, h) experiências institucionais (instituições, polícia, justiça, mídia, sistema educativo, emprego). Em conjunto, esses fatores são úteis para explicar a heterogeneidade de perfis de crianças em situação de rua, bem como a diversidade das trajetórias pessoais, ideia considerada central para a definição de intervenções voltadas a essa população.

Em termos de políticas de proteção às crianças e adolescentes que se encontram em situação de rua, algumas recomendações são feitas. A primeira trata da adoção de serviços que sejam mais abrangentes (oportunidade de moradia, educacional, profissionalização e de trabalho) e com menor caráter compensatório (serviços de subsistência, por exemplo). A segunda implicação é a de que os serviços para as populações em situação de rua deveriam ser mais dispersos geograficamente, ao invés de estar limitado a áreas/regiões específicas das cidades. A terceira implicação refere-se à necessidade de que os profissionais que lidam com a população em situação de rua tenham treinamento em áreas específicas, tais como a de comportamentos de risco à saúde. E, por fim, a quarta recomendação é a de que mais alternativas de stable housing (habitação estável) sejam oferecidas aos jovens em situação de rua (Repúblicas, por exemplo) e que os serviços atuassem de forma mais coordenada, capacitando os jovens a viverem nesses espaços, enquanto continuam construindo alternativas que os levem à independência e 
autonomia (Morais \& Koller, 2012; Milburn, Rosenthal, \& RotheramBorus, 2005).

Nesse sentido, o acolhimento institucional (nas suas diferentes modalidades) constitui-se com uma alternativa possível (e não a única), legalmente prevista para a população infanto-juvenil em situação de rua (Siqueira, Morais, Dell' Aglio, \& Koller, 2010). No entanto, as diretrizes que orientam o acolhimento de crianças e adolescentes em situação de rua são as mesmas que norteiam a atenção de crianças/adolescentes que vivenciam outras situações de vulnerabilidade (violência física, violência sexual, abandono e negligência, por exemplo). São elas: a excepcionalidade e provisoriedade do afastamento do convívio familiar; preservação e fortalecimento dos vínculos familiares e comunitários; garantia de acesso e respeito à diversidade e não discriminação; oferta de atendimento personalizado e individualizado; garantia de liberdade de crença e religião; e respeito à autonomia da criança, do adolescente e do jovem (Conselho Nacional dos Direitos da Criança e do Adolescente/Conselho Nacional de Assistência Social [CONANDA/ CNAS], 2008; Estatuto da Criança e do Adolescente [ECA], 1990; Siqueira \& Dell'Aglio, 2010) .

Em consonância com o Plano Nacional de Promoção, Proteção e Defesa do Direito de Crianças e Adolescentes no que se refere à Convivência Familiar e Comunitária; e com o Estatuto da Criança e do Adolescente (ECA), tem-se que os serviços de atendimento às crianças e adolescentes em situação de rua devem se organizar de forma a garantir a centralidade da família nas políticas públicas, sendo que toda e qualquer ação deve ter a família como base e não apenas a criança/adolescente em situação de rua atendida. Além disso, ao Estado cabe a primazia da responsabilidade no fomento de políticas integradas de apoio à família; e a família deve ser reconhecida em suas competências, na sua organização interna e na superação de suas dificuldades (CONANDA/CNAS, 2006). Todas essas diretrizes, portanto, implicam a necessidade de se trabalhar 0 processo de reinserção familiar das crianças e adolescentes institucionalizadas (com histórico de situação de rua) às suas famílias. O acolhimento, embora necessário como medida de proteção à violação dos direitos anteriormente sofrida, é excepcional e temporária; não devendo durar mais que o período legalmente estipulado, que é o de dois anos (ECA, 1990).

Ao processo de saída de um serviço de acolhimento e o retorno à família (seja ela a de origem, a extensa ou a adotiva), dá-se o nome de reinserção familiar. Trata-se de um tema bastante importante no cotidiano das instituições e central nas normas legais que orientam o atendimento nesses espaços, constituindo-se como uma área complexa no que diz respeito às políticas públicas de proteção ao bem estar desta população. Ademais, entende-se que a reinserção 
familiar não deve ser entendida apenas como reunião física de crianças e adolescentes, que estavam sob cuidados não-familiares, às suas famílias de origem, mas abrange um entendimento mais amplo, enquanto reunificação psicológica (Maluccio, Warsh, \& Pine, 1993; Siqueira \& Dell'Aglio, 2011).

Uma série de medidas são propostas para que sejam mantidos os vínculos afetivos das crianças e adolescentes institucionalizados com seus familiares, sendo responsabilidade da equipe das instituições de acolhimento a promoção, a avaliação e a preparação dos processos de reinserção familiar (ECA, 1990; Siqueira, 2012). Esse processo planejado de reconexão de crianças e adolescentes com suas famílias se faz através de uma variedade de serviços e apoio não somente às crianças, mas, também, às suas famílias, aos cuidadores substitutos e a outras pessoas envolvidas nesse processo. Portanto, promover esta política de reinserção familiar é agir em prol da conservação dos laços afetivos familiares e do sentimento de conexão da criança com os membros da sua família, mesmo antes da reunião física (Maluccio, Warsh, \& Pine, 1993; Siqueira \& Dell'Aglio, 2011).

No caso do trabalho com crianças e adolescentes em situação de rua há uma necessidade da articulação permanente com educadores de rua, com o Conselho Tutelar, com a rede de saúde e educação. A articulação com a área de educação possibilitará, assim, o planejamento de uma reinserção gradativa da criança e do adolescente na rede de ensino. Já a área da saúde estará nesse processo de reinserção familiar quando incluir a capacitação continuada e o acompanhamento dos profissionais do acolhimento em relação aos cuidados adequados a crianças e adolescentes com histórico de uso, abuso ou dependência de álcool e outras drogas, além de disponibilizar aos usuários atendimento especializado, inclusive em saúde mental, quando necessário. Tanto o trabalho de aproximação quanto 0 acolhimento propriamente dito têm como objetivo reintroduzir a criança e o adolescente gradativamente em uma rotina doméstica, resgatando o convívio familiar e comunitário, reinserindo-os na rede social como um todo - saúde, educação, lazer, etc. (CONANDA/CNAS, 2006).

Estudo anterior realizado sobre reinserção familiar no contexto brasileiro, por exemplo, mostrou que as maiores dificuldades para o retorno das crianças e adolescentes às suas famílias de origem, relatadas pelos dirigentes de acolhimentos são: as precárias condições socioeconômicas, a fragilidade, ausência ou perda do vínculo familiar e a ausência de políticas públicas e de ações institucionais de apoio à reestruturação familiar, entre outros (Siqueira, Massignan, \& Dell'Aglio, 2011).

Essas mesmas autoras indicaram a existência de expressivos e numerosos fatores de risco no ambiente familiar, a saber: a situação de vulnerabilidade social das famílias quando da volta das 
crianças/adolescentes; a não preparação dos jovens e familiares para o retorno; e a não disponibilização de apoio aos egressos após o desligamento da instituição. Alguns adolescentes demonstraram satisfação com a reinserção após alguns meses de desligamento, embora a situação de pobreza e baixo desempenho escolar fossem percebidos como problemas pelos participantes (Siqueira \& Dell'Aglio, 2007, 2011).

Brito, Rosa e Trindade (2014), indicaram em seu estudo que o processo de reinserção familiar traça o seguinte percurso: acolhimento inicial, com identificação da história de vida da criança ou do adolescente e dos seus núcleos familiares; realização de visitas familiares com vistas à avaliação sobre a possibilidade de efetivação do processo; encaminhamentos para a rede sócio-assistencial; e visitas domiciliares. Outros estudos mostraram que não existe um programa de avaliação e acompanhamento de egressos dos acolhimentos e, muitas vezes, as instituições de acolhimento não possuem equipe ou habilitação técnica para realizar este trabalho (Siqueira \& Dell'Aglio, 2007, 2011). A prática de promover visitas periódicas entre os abrigados e seus familiares foi encontrada na totalidade dos casos, contudo, se não forem planejadas em conjunto com as famílias e estas não forem orientadas e ajudadas nesse processo de reconexão, as visitas não serão um importante instrumento para o sucesso na reinserção. De fato, as instituições que possuem assistentes sociais, psicólogos e educadores sociais, parecem realizar esta avaliação e acompanhar o desligamento. Porém, este trabalho acaba sendo um entre tantos outros que a equipe deve realizar, de forma que se pode afirmar que existe uma dificuldade para efetivar a determinação legal em sua plenitude.

A reflexão trazida pelas equipes técnicas a respeito do tempo (tempo da criança na instituição, morosidade da justiça e falta de tempo da equipe técnica para promover as ações necessárias com a família) revela ser este um dos pontos de tensão a ser enfrentado e resolvido na questão da reinserção familiar. O desdobramento de se praticar o princípio da excepcionalidade e da brevidade na instituição de acolhimento acarreta uma rearticulação entre a instituição e sua rede de apoio, incluindo a justiça. Praticando o melhor interesse da criança as equipes precisam receber o reforço no número de profissionais e ter uma atuação mais conjunta com o poder jurídico (Brito, Rosa, \& Trindade, 2014).

Com base no exposto acima e considerando a necessidade/relevância de estudos que tratem da reinserção familiar de adolescentes com experiência prévia de situação de rua, o presente artigo buscou realizar uma análise das expectativas acerca da reinserção familiar de adolescentes institucionalizados com histórico de situação de rua, a partir da perspectiva de três categorias de participantes - os adolescentes, seus familiares e educadores sociais no mês que 
antecedeu a saída da instituição. Entende-se que a compreensão das expectativas é central, uma vez que pode desvelar as preocupações e sentimentos envoltos nesse importante momento da vida dos adolescentes. Ademais, a possibilidade de escutar a percepção dos próprios adolescentes e de importantes protagonistas do processo de reinserção familiar (familiares e educadores) certamente permitirá uma visão mais abrangente acerca da RF.

\section{Método}

\subsection{Participantes}

Participaram deste estudo cinco adolescentes do sexo masculino com histórico de rua e em situação de acolhimento institucional; seus familiares - irmãos, mãe e avós; e dois educadores sociais. Todos os adolescentes tinham 14 anos de idade e foram escolhidos para participarem desse estudo porque se encontravam no processo de reinserção familiar (mês de julho de 2013). A idade dos familiares entrevistados variou de 16-75 anos e a dos educadores variou de 4529.

\subsection{Lócus do estudo}

A instituição onde o presente estudo foi realizado (Acolhimento Institucional) foi selecionada devido à sua abertura a trabalhos de pesquisa dessa natureza. Trata-se de uma Organização Não Governamental (ONG) que, desde o ano de 1994, existe na cidade de Fortaleza, sendo reconhecida na cidade pelo serviço prestado a meninos em situação de moradia nas ruas. A ONG trabalha no processo de reinserção familiar e comunitária de crianças/adolescentes em situação de moradia nas ruas, buscando promover a garantia dos direitos fundamentais dos assistidos e suas famílias, bem como a inclusão social dos mesmos.

\subsection{Instrumentos}

Foram utilizados três roteiros de entrevistas semiestruturadas, especialmente elaboradas para esse estudo, os quais foram utilizados com os adolescentes, familiares e educadores. O roteiro de entrevista com os adolescentes abrangeu quatro temas: 1) motivos que levaram à sua institucionalização; 2) percepção acerca de atividades realizadas e relações estabelecidas naquele contexto (atividades que estão exercendo, relação com as outras crianças, adolescentes, profissionais e educadores sociais que os acompanham na instituição antes do processo de reinserção familiar); 3) relação com os seus 
familiares durante a institucionalização; e 4) expectativas e sentimentos quanto ao retorno para casa e comunidade.

Com os familiares dos adolescentes em estudo, a entrevista semiestruturada buscou descrever: 1) motivos que levaram à institucionalização do adolescente; 2) a relação familiar (antes e durante a institucionalização); 3) o conhecimento sobre o adolescente (características, dificuldades, aptidões); e 4) expectativas e sentimentos quanto ao retorno dos adolescentes.

A entrevista com os educadores sociais focou no: 1) conhecimento do educador sobre o adolescente e seus familiares; 2) os motivos de entrada e período de adaptação institucional; 3) o contato com os demais adolescentes e funcionários; e 4) as expectativas sobre a volta do adolescente para a casa e a relação familiar.

\subsection{Procedimento de coleta de dados}

A realização da pesquisa envolveu, principalmente, a Inserção Ecológica da primeira autora na instituição e famílias dos adolescentes participantes. A Inserção Ecológica é um método que privilegia a inserção dos pesquisadores no ambiente de pesquisa, com o objetivo de estabelecer proximidade com o seu objeto de estudo e, assim, responder às questões de pesquisa. Além disso, por está baseada na abordagem bioecológica, a Inserção Ecológica prevê a sistematização dos quatro núcleos propostos por Bronfenbrenner: processo, pessoa, contexto e tempo. Por fim, além de possibilitar a realização de uma pesquisa no ambiente natural, com validade ecológica, a inserção proporciona a ocorrência de um processo de interação social, atuando como intervenção, seja através dos aconselhamentos e/ou encaminhamentos realizados (Cecconello \& Koller, 2003; Morais, 2009). A inserção do pesquisador no ambiente de pesquisa amplia as possibilidades explicativas do estudo, uma vez que suas impressões poderão funcionar como uma fonte complementar de dados do processo proximal do pesquisador (Santana, Doninelli, Frosi, \& Koller, 2004).

Após receber o consentimento da instituição, os adolescentes foram convidados a participar da pesquisa, assim como o familiar dele e o educador responsável. Todos os adolescentes da instituição que estavam se preparando para voltarem para casa quando da realização da pesquisa foram entrevistados. Para cada adolescente, buscou-se identificar o familiar responsável que poderia conceder a entrevista, assim como o educador que, na instituição, tinha a responsabilidade de acompanhá-los diariamente, exercendo a função de pai-social. Todas as entrevistas foram realizadas individualmente, sendo que adolescente e educador foram entrevistados na instituição; e o familiar na sua residência. As entrevistas dos adolescentes duraram em média 20 minutos e a dos familiares e educadores 35 
minutos. Todas as entrevistas foram gravadas e transcritas para posterior análise.

\subsection{Procedimentos de análise de dados}

Foi realizada a Análise de Conteúdo (Bardin, 1977/1979), a qual compreendeu três fases: 1) pré-análise, 2) exploração do material e 3) tratamento dos resultados, inferência e interpretação. A préanálise é a fase em que se organiza o material a ser analisado com o objetivo de torná-lo operacional, sistematizando as ideias iniciais. A exploração do material consiste na definição de categorias (sistemas de codificação) e a identificação das unidades de registro e das unidades de contexto nos documentos submetido a um estudo aprofundado, orientado pelas hipóteses e referenciais. O tratamento dos resultados, inferência e interpretação, condensa e destaca as informações para análise, resultando nas interpretações inferenciais; é o momento da intuição, da análise reflexiva e crítica.

\subsection{Procedimentos éticos}

A presente pesquisa foi aprovada no Comitê de Ética da Universidade. Os procedimentos de consentimento utilizados nesta pesquisa obedeceram aos Critérios da Ética na Pesquisa com Seres Humanos, pautados na Resolução 196/1996 (até então vigente à época de aprovação do Projeto), do Conselho Nacional de Saúde e ao Estatuto da Criança e do Adolescente (Brasil, 1990).

No caso dos adolescentes, solicitou-se autorização para realização da pesquisa junto ao Ministério Público Estadual, a assinatura do Termo de Concordância para a instituição em que ocorreu a inserção da equipe de pesquisa e o assentimento de cada adolescente recrutado para participar da pesquisa. No que se refere aos familiares e educadores entrevistados, solicitou-se a assinatura do Termo de Consentimento Livre e Esclarecido para ambos.

\section{Resultados}

A descrição dos resultados acerca das expectativas e sentimentos será feita considerando as perspectivas dos três participantes (adolescentes, familiares e educadores) separadamente. Todos os nomes mencionados são fictícios para efeitos de sigilo da identidade dos participantes.

\subsection{A Perspectiva dos adolescentes}


Considerando as expectativas em voltar para casa, os adolescentes descreveram-se como ansiosos em reencontrar os familiares e de recomeçarem a viver junto a eles. Neste momento da entrevista, todos mostraram a vontade de sair do acolhimento e ficar definitivamente com a família, sem intenção de se reinstitucionalizar. Além disso, não relataram conflitos e dificuldades, como se pode verificar na frase abaixo:

O que tem de bom? Voltar pra minha família de novo. O que tem de ruim? Nada [...] Eles [familiares] tão alegre, né? Me esperando, porque já faz é tempo que eles num me veem e eu num vejo eles (Marcos).

Mas eu num voltaria não [para o abrigo] Por quê? Por causa da família, né? (Leandro).

Daniel foi o único adolescente que mostrou pouca empolgação pelo retorno familiar. Nota-se esse aspecto através das falas: "Até agora eu só sei que eu vou morar mais a minha irmã" ou "Acho que vai ser muito difícil. Acho que num vou nem sair de casa" e ainda repetiu várias vezes: "Ninguém me espera não".

No que concerne à expectativa pela volta ao contexto familiar, os adolescentes expressaram entusiasmo em trabalhar e colaborar com as despesas de casa. "Que eu vou trabalhar, né? Ajudar a minha família, ajudar a minha mãe. Pra arranjar uma casinha pra nós" (Paulo).

Além disso, determinaram como "ultrapassadas" e superadas as dificuldades pessoais e do microssistema familiar que levaram à institucionalização.

Agora, né, já tem tudo lá em casa, já. [...] Mudou, tia. Antes eu era muito danado... a vó falava e eu ficava respondendo ela. Agora não, ela fala e eu fico calado (Marcos).

Quero trabalhar, estudar... Tentar ficar longe de ver as pessoas usando droga. Tentar ir pra igreja. Igreja... Lá pertim de casa. Tentar não usar droga, né... (Francisco).

Diante das expectativas, Leandro e Daniel trouxeram no discurso aspectos negativos que se contrapuseram aos demais adolescentes entrevistados. Apesar de terem passado anos institucionalizados estavam conscientes sobre as dificuldades que encontrariam quando da volta para casa.

Coisa ruim em voltar pra casa? As drogas, tia (Leandro).

Vou encontrar a minha família... é... na miséria. [...] Sei não, tia. Do mesmo jeito, né? Do mesmo jeito que era antes. Mesma vida (Daniel). 
Considerando as expectativas repletas de sentimentos negativos que ocorrem nesse período próximo à reinserção familiar, todos os adolescentes apresentaram o medo, insegurança e a ansiedade de repetir as experiências que os fizeram sair de casa. Esse aspecto se reforça tanto na família, como na comunidade onde estão inseridos.

Tenho medo que a minha mãe pode ir lá botar o maior "queixo" [Para voltar a trabalhar nos terminais para integração de ônibus vendendo bombons] (Daniel).

Tudo o que tem pra encontrar de ruim tá lá. [...] As drogas lá... $\mathrm{Na}$ rua tem é muito. E dentro de casa também. É... Meu tio e minha tia tudo fuma dentro de casa lá. Quando eu tava lá, meu tio tava ameaçado (Leandro).

Encontrar a minha casa toda desarrumada. Só isso. Minha mãe usando droga. Em péssimo estado (Francisco).

Mesmo com receio diante dessas dificuldades, os adolescentes recuperavam em suas falas, logo em seguida, as expectativas atuais e a vontade de mudar a si mesmos.

Não, meu medo é dizer não, porque eles podem até fazer alguma coisa comigo, né? Tem perigo não, tia, eu cair em tentação (Marcos).

Tia, o Paulo pequeno só pensava em brincar, e agora esse Paulo grande pensa em...Pensa em estudar... Trabalhar... Ter uma vida boa (Paulo).

Eu era magro, sujo, pura solvente pensava em melhorar minha vida. Agora tá bom, mas ele tá rebelde. Ficou mais experiente (Francisco).

Daniel foi o único adolescente que continuou com o sentimento de angústia e indecisão sobre o seu processo de reinserção familiar. Acreditava que ainda permaneceria mais algum tempo no Al. Quando descrevia esse sentimento mantinha a cabeça baixa, não conseguindo olhar, em nenhum momento, para os olhos da pesquisadora "Vai ser muito difícil [...] quem me espera? Ninguém me espera".

\subsection{A Perspectiva dos familiares}

No início da entrevista os familiares manifestaram uma crença nas mudanças de comportamento dos adolescentes, uma vez que tinham a impressão de que os mesmos ainda passariam algum tempo institucionalizados. Quando lembrados que faltava um mês para acolherem os adolescentes, pois já tinham idade para voltar para casa (o prazo para ficarem no acolhimento institucional são os 14 
anos), os familiares mudaram o discurso e mostraram-se preocupados com esse retorno familiar. Assim, revelaram-se intolerantes caso o adolescente fizesse algo que os desagradassem:

O Marcos é uma benção. O Marcos é um abençoado quando ele tá aqui [Al], né? Mas quando ele chega em casa ele muda demais. Quer se soltar. Se ele der trabalho, nem sei o que fazer, mandar pra onde? (D. Zefa - Avó Paterna de Marcos).

D. Ana (Avó materna de Leandro) não acreditava na mudança do adolescente e já expressava preocupação em ocupá-lo para ajudar dentro de casa:

Ah, acho que é bom se ele voltar, né...Agora, oh, ele num melhora mais do que isso não, viu? Não. Ah, vou esperar o Leandro melhorar pra arrumar um emprego. Por enquanto, não. Ele já fez três entrevistas e não passou em nenhuma. Agora se ele num estudar, bora, você vai trabalhar pra mim ajudar. [...] Eu tenho muito medo. Muito medo mesmo.

Mara (Irmã de Daniel) e D. Maria (Mãe de Paulo) estavam empolgadas com o retorno familiar, mas só enxergavam as facilidades da convivência, deixando de lado os obstáculos:

Não, acho que num vai ter dificuldade não. Ele é um menino muito calmo, acho que num vai ter problema não (Mara - Irmã de Daniel).

Vai ter dificuldade não, se Deus quiser. Porque eu me esforço, trabalho, não tenho preguiça de trabalhar. Eu só quero que ele me dê amor e carinho. E atenção. O resto, Deus me ajuda (D. Maria - Mãe de Paulo).

Todos os familiares tinham esperança na possibilidade dos adolescentes voltarem para casa trabalhando e assim ajudar nas despesas da casa e ocuparem o tempo livre.

Me ajudar, vai ter de ajudar o pai dele, né? Trabalhar, ajudar o pai dele. Ele tem um pensamento muito bom, ele disse: "quando eu trabalhar, mamãe, eu vou ajudar a senhora e ajudar o pai" (D. Zefa - Avó Marcos).

Eu ainda nem parei pra pensar nisso... A gente pouco vai ter tempo, ele já vem trabalhando e estudando, e eu também do mesmo jeito (Mara - Irmã Daniel).

Diego, quando perguntado pela expectativa da volta do irmão Francisco, mostrou-se preocupado. As condições físicas da casa, a 
violência na comunidade, tráfico e o uso de drogas por parte da mãe foram colocados como obstáculos.

Eu vou falar de mim. Eu tô esperando ele vim, sabe, se der certo mesmo, né? [...] Vai ser difícil, sabe? É como tá na UTI, tá entendendo? [...] Depois que eu voltei da clínica, é difícil eu ir pra lá [casa da mãe]. Mas eu entrei uma vez lá, e tá tudo como tava. No corredor, sabe, aquela sujeira, sabe? Eu tava até comentando com a minha namorada que quando eu cheguei da clínica tava tudo sujo, aí eu emburaquei pra minha vó. Além da sujeira lá de casa, é o modo como ele vai ser tratado. Se ele for voltar pra lá, é melhor ele passar um tempo na vó, tá entendendo? [...] Lá em casa, lá em casa, eu num sei não. É ruim. O estado que tá, né, a violência que tá ocorrendo em todo canto [...]. (Diego - Irmão de Francisco)

\subsection{A Perspectiva dos educadores sociais}

O educador Bento quando perguntado sobre a expectativa da reinserção familiar, nos cinco casos, relacionou as dificuldades desse processo com o uso de drogas por parte dos familiares ou dos adolescentes, deixando claro que o desafio para a reinserção familiar é o histórico de uso de drogas:

O Marcos nunca, desde quando ele tá aqui, ele nunca teve um envolvimento com coisas erradas. As mais erradas que a gente fala, né... cigarro, droga... eu pelo menos nunca ouvi falar dele envolvido com isso. Em casa, ele vem, as saídas dele são tranquilas. Então, eu acho que já tá na época.

[...] O Daniel tem muito a ver com o irmão, que um menino assim muito responsável. Eles não vieram pra cá por envolvimento com droga, foi só a questão da mãe, a exploração, né... Eu acho que ele vai conseguir. O retorno pra família vai ser... hoje, pra mim, vai ser o mais complicado.

Da mesma forma dos adolescentes e familiares, o educador apresenta em seu discurso uma grande expectativa e preocupação pelo primeiro emprego dos adolescentes, principalmente quando essa será a forma de sustento da família. Nesse aspecto o educador também expõe a "maturidade" e o tempo certo para entrar no mercado de trabalho, pois alguns meninos não estão preparados para assumir a responsabilidade, mas se veem obrigados a aceitar, pois é a oportunidade que têm para voltar para a casa dos familiares e sair da instituição. 
[Marcos] nunca demonstrou vontade de voltar pra casa sem ter uma ocupação. Parece ele é bem crescido... Imaginar que o trabalho vai ser uma ótima ajuda pra ele.

É difícil a gente entender o que o Leandro realmente quer da vida. Por exemplo, a questão do emprego, será que é isso mesmo que o Leandro tá querendo? Porque você olhando assim pra ele, ele é uma pessoa arredia, morta, parece que o emprego é só uma aventura, que é só passear depois de sair do sítio... Você não percebe ainda a responsabilidade que ele tem.

Eu acho que... eu não sei hoje da situação da família, a situação da mãe dele [Paulo]... Mas eu acho que ele vai dar certo, certamente vai passar um período lá na casa [outra instituição de acolhimento] ainda, até que ele amadureça mais um pouco essa parte profissional.

Mesmo com a expectativa de sucesso no retorno familiar, Bento corroborou o sentimento de angústia e insegurança expressos por Daniel sobre a sua volta para casa. O educador deixou claro que a família desse adolescente não estava preparada para acolhê-lo e que o adolescente não estava empolgado para voltar para a família.

Ele ainda num demonstra nenhuma vontade de sair daqui, pelo menos, agora. [...] ele nem disse diretamente que queria sair, mas parece que quando vem assim à mente as coisas que ele passou, aí dá logo vontade de desistir, né...? Parece que ele ainda tem medo de chegar lá e acontecer alguma coisa.

\section{Discussão}

De acordo com os resultados descritos acima, foi possível notar que, em geral, os adolescentes apresentaram expectativas mais positivas sobre a reinserção familiar quando comparados aos seus familiares e educadores sociais. De acordo com os adolescentes, a possibilidade de ficar perto dos familiares e manter o bom comportamento, sem se envolver com as situações de risco existentes na comunidade ajudaria a manter uma melhor convivência com a família de origem.

Diferente dos adolescentes, os familiares e educadores mencionaram mais frequentemente as dificuldades e limites do contexto (uso de drogas, falta de habitação e a violência na comunidade, por exemplo), os quais estavam relacionados aos motivos da institucionalização dos adolescentes, mas que ainda se faziam presentes no momento de preparação para a reinserção familiar (um mês antes da saída da instituição). Mas, assim como os adolescentes, os familiares e educadores sociais visualizaram no emprego de 
"jovem aprendiz" a possibilidade de ajudar e mudar a situação familiar, além de ocupar diariamente o adolescente, evitando o tempo livre e consequentemente o contato com a violência e drogas na comunidade.

A oportunidade de emprego é considerada uma das maiores preocupações na vida de jovens em qualquer estratificação social. Ao levar em consideração adolescentes/jovens em vulnerabilidade social, as formas de trabalho são exercidas com precariedade e a grande maioria na informalidade, sem nenhuma proteção e expectativa de futuro. Motivados pela necessidade de obter renda para subsistência própria e/ou da família, ou acesso aos bens impostos a todos pela sociedade do consumo, ou pela descrença nos estudos como propulsor de melhores condições de vida no futuro e considerando-se o agravante de que muitas vezes a escola é mais entediante do que motivadora e criativa, não lhes é garantida a oportunidade ao trabalho decente (Gonçalves, 2014).

A proposta apresentada na Lei 10.097 de dezembro de 2000 assume quatro pontos importantes para o trabalho com jovem aprendiz em seu primeiro emprego: 1) Mais e Melhor Educação; 2) Conciliação de Estudos, Trabalho e Vida Familiar; 3) Inserção Ativa e Digna no Mundo do Trabalho; e 4) Diálogo Social. Esses pontos deveriam nortear toda a oferta de oportunidades de trabalho para adolescentes e jovens, em especial por ocasião de suas primeiras experiências, sem 0 que praticamente não existem reais perspectivas de crescimento ou de boas trajetórias, tais como: a inclusão no mundo laboral, realizada por vagas de estágio, trainee ou em outras ações empreendedoras, a condição especial desse momento da vida merece um olhar especial da sociedade e do mercado de trabalho (Gonçalves, 2014).

Considerando-se as esporádicas visitas dos familiares aos adolescentes durante o período em que estiveram institucionalizados, assim como o pouco tempo disponibilizado para estes encontros, acredita-se que os adolescentes não costumavam se deparar com as reais condições de vulnerabilidade em que suas famílias seguiam vivendo. Dessa forma, o processo de volta para casa e as expectativas mais positivas do que negativas dos adolescentes se relacionavam com o distanciamento dos aspectos negativos da família e da comunidade enquanto estavam acolhidos.

Ressalta-se aqui a importância da realização de um trabalho da equipe institucional em fortalecer os vínculos familiares dos adolescentes com histórico de situação de rua. Estudos apontam que este é um fator primordial a ser considerado na descrição e no trabalho com o público que está em situação de rua. A maioria das crianças e adolescentes encontrada na rua não é abandonada, pois, geralmente, mantém um ponto de referência com relação ao grupo familiar e, mesmo após a saída de suas casas, os jovens "em situação 
de rua" mantêm contato com suas famílias. Esses vínculos devem ser analisados de forma dinâmica e contínua, devido às frequentes oscilações no grau e na configuração. Por isso é importante frisar que ao abordar a realidade vivida por essa população e por suas famílias é preciso refletir e trabalhar com a família contextualizada (Paludo \& Koller, 2008).

A crença da instituição enquanto um local apropriado para o desenvolvimento das crianças, pelas famílias e por membros do poder jurídico, tem sido um fator que dificulta a desinstitucionalização das crianças e adolescentes. Dessa forma, tem-se verificado que a retirada das crianças das famílias tem sido mais rápida do que a saída da instituição de acolhimento, o que mostra uma rigidez por parte das equipes técnicas, coordenadores, políticas publicas e dos familiares nas ações para promoção da reinserção familiar (Brito, Rosa, \& Trindade, 2014).

O afastamento do convívio familiar é uma medida excepcional e provisória que visa garantir a proteção da criança/adolescente de diferentes situações que implicam a violação dos seus direitos. Mesmo com o ambiente institucional garantindo proteção e os direitos fundamentais, verificou-se na fala dos adolescentes participantes desse estudo o desejo de retornar para o convívio familiar. No entanto, para que esse retorno seja viável, tanto a comunidade, os seus serviços de atendimento e apoio, como as famílias precisam se reorganizar e se fortalecer. É necessário uma mudança cultural e um esforço da sociedade para desconstruir a crença de que essas famílias são incapazes e desqualificadas para o cuidado de seus filhos. Para isso, é preciso que os programas de atendimento sejam eficazes a fim de potencializar a família e a comunidade como um sistema social capaz de promover bem-estar entre seus membros (Morais, Paludo, \& Koller, 2010).

Outro aspecto importante é a relação entre a idade em que ocorreu a institucionalização e as expectativas positivas. Os adolescentes (no momento da coleta de dados estavam com 14 anos) foram acolhidos ainda crianças e criaram uma imagem ideal do seu contexto familiar pautando-se nos momentos de férias, visitas ou ainda em discussões sobre família traçados pelos educadores e técnicos do Acolhimento Institucional. Essa família ideal baseia-se na tradição, uma noção que já é trazida pelo grupo social, pelas instituições ou pela mídia. A família vivida leva em consideração os modos habituais de agir dos membros que aparecem no cotidiano (Yunes, Arrieche, Tavares, \& Faria, 2001). Nesse sentido, a descrição feita pelas famílias e educadores aproxima-se muito mais da família vivida dos adolescentes acolhidos, sobretudo porque contempla os aspectos de vulnerabilidade do grupo familiar e comunidade em que vivem (dependência química, violência, trabalho infantil, dentre outros). 
Em conjunto, os resultados evidenciam a ausência ou a incipiência de mudanças significativas nas condições de vulnerabilidade que caracterizavam as famílias dos adolescentes acolhidos desde a sua institucionalização. Ou seja, as mesmas condições que motivaram a institucionalização continuavam a marcar o contexto familiar, no mês anterior à reinserção familiar ser efetivada.

\section{Considerações finais}

O artigo buscou analisar as expectativas de adolescentes, familiares e educadores acerca do processo de reinserção familiar dos primeiros. Para isso, os três protagonistas foram entrevistados um mês antes da reinserção familiar acontecer. Acredita-se que os resultados permitiram aprofundar a temática da reinserção familiar, sobretudo em virtude de suas contribuições a esse campo de estudos. Primeiramente, destaca-se a inclusão de três atores fundamentais ao processo de RF (adolescentes, familiares e educadores). E, por fim, o uso da estratégia metodológica da Inserção Ecológica para realização da pesquisa.

Considerando que a maioria dos estudos prévios acerca da RF tende a privilegiar a perspectiva de apenas um participante (quase sempre a criança/adolescente reinserido) e em um único momento do tempo (após a saída da instituição), esperava-se com a realização da presente pesquisa, contribuir com uma perspectiva mais sistêmica, holística e contextualizada da reinserção familiar. No entanto, infelizmente, não foi possível entrevistar adolescentes do sexo feminino nesse estudo, fato que embora esteja relacionado ao perfil da população em situação de rua - majoritariamente masculina agregaria maior riqueza a esse estudo. Nesse sentido, sugere-se que estudos posteriores incluam participantes do sexo feminino na sua amostra e que busquem descrever a reinserção desde a entrada no acolhimento institucional.

Especificamente, sobre os resultados do estudo, percebeu-se que as expectativas dos adolescentes no momento que antecede a saída da instituição tende a ser mais positiva quando comparada a dos seus familiares e educadores sociais. No entanto, os adolescentes também se descreveram com medo, inseguros e ansiosos para voltarem para casa. Enquanto os adolescentes mencionaram 0 desejo de reencontrar os familiares, tanto estes quanto os educadores frisaram as dificuldades e limites do contexto (uso de drogas, falta de habitação e a violência na comunidade). Diante do exposto, pode-se sugerir que a provisoriedade da reinserção familiar (máximo de 2 anos, segundo o ECA) é um desejo que tende se expressar mais fortemente no discurso do adolescente institucionalizado. 
Os adolescentes exprimem de diversas formas (falas e comportamentos na instituição) o desejo pelo retorno às famílias, através de mudanças no comportamento (agressividade, isolamento, tentativas de fuga), nas relações conflituosas com os pares e educadores sociais, no desenvolvimento nas atividades e na ansiedade em rever os familiares. À vista disto há uma carência de relações com a família e também com a comunidade, fato que deveria ser uma preocupação de todo e qualquer serviço de acolhimento institucional; desde o momento de ingresso da criança/adolescente. Inclusive, a legislação brasileira (Lei No. 8.069/1990; Lei No. 12.010/2009), obriga as entidades a desenvolverem programas de acolhimento institucional que incentivem 0 restabelecimento e a preservação dos vínculos familiares, bem como comunicar às autoridades do Sistema de Justiça, periodicamente, os casos em que se mostre inviável ou impossível o reatamento dos vínculos familiares.

Dado que a reinserção familiar não é somente a reunificação física do adolescente a seus familiares, mas, também, um processo gradual de reinserção psicológica, acredita-se que é de fundamental importância que a mesma seja trabalhada desde o primeiro dia em que o adolescente é acolhido; e, inclusive, após o regresso ao convívio familiar. Uma vez que não se fortalece ou refaz vínculos afetivos abruptamente, a RF deve ser preparada. Infelizmente, porém, essa não parece ser realidade constatada na experiência dos adolescentes que foram entrevistados nesse estudo e de suas famílias. $O$ descompasso entre as expectativas dos participantes, seus familiares e educadores não condiz com o fato de que em um mês os adolescentes estariam sendo reinseridos em suas famílias.

Conclui-se corroborando a complexidade da reinserção familiar, a qual envolve múltiplos sujeitos em diferentes contextos, os quais precisam ser trabalhados conjuntamente. Nesse caso, é essencial realizar a preparação da família e do próprio adolescente de forma gradual e agregadora, com atendimentos sistêmicos, que incluam a intervenção no contexto familiar. Dessa forma, a reinserção poderia iniciar-se com visitas periódicas, começando nas férias, depois mensalmente e finais de semana. As intervenções deveriam, ainda, envolver o contexto comunitário, principalmente por meio do fortalecimento das redes de proteção comunitária e da integração das famílias a estas.

\section{Referências}

Bardin, L. (1979). Análise de Conteúdo. (L. Reto \& A. Pinheiro, Trad.). São Paulo: Edições 70, Livraria Martins Fontes (Originalmente publicado em 1977). 
Brito, C. O. D., Rosa, E. M., \& Trindade, Z. A. (2014). O processo de reinserção familiar sob a ótica das equipes técnicas das instituições de acolhimento. Temas em Psicologia, 22(2), 401413.

Cecconello, A. M. \& Koller, S. H. (2003). Inserção ecológica na comunidade: uma proposta metodológica para o estudo de famílias em situação de risco. Psicologia: Reflexão e Crítica, 16(3), 515-524.

Conselho Nacional dos Direitos da Criança e do Adolescente /Conselho Nacional de Assistência Social. (2008). Orientações Técnicas para os Serviços e acolhimento para crianças e adolescentes. Ministério do desenvolvimento social e combate à fome, secretaria especial de direitos humanos. Brasília.

Conselho Nacional dos Direitos da Criança e do Adolescente / Conselho Nacional de Assistência Social. (2006). Plano Nacional de Promoção, Defesa e Garantia do Direito de Crianças e Adolescentes à Convivência Familiar e Comunitária. Ministério do desenvolvimento social e combate à fome, secretaria especial de direitos humanos. Brasília.

Gonçalves, A. L. A. (2014). Aprendizagem profissional: trabalho e desenvolvimento social e econômico. Estudos Avançados, 28(81), 191-200.

Lei n. 8.069 de 13 de julho de 1990. Estatuto da Criança e do Adolescente (1990). Brasília, DF: Câmara dos Deputados.

Lei n. 12.010 de 03 de agosto de 2009. Lei do Direito à Convivência Familiar da criança e do adolescente. Brasília, DF: Congresso Nacional.

Lucchini, R. (2003). A criança em situação de rua: uma realidade complexa. In I. Rizzini (Org.), Vida nas ruas: crianças e adolescentes nas ruas: trajetórias inevitáveis? (pp. 45-86). Rio de Janeiro/São Paulo: PUC-Rio/Loyola.

Maluccio, A. N., Warsh, R., \& Pine, B. (1993). Rethinking family reunification after foster care: Community Alternatives. International J ournal of Family Care, 5(2), 1-17.

Morais, N. A. (2009). Trajetórias de vida de crianças e adolescentes em situação de vulnerabilidade social: entre o risco e a proteção. Tese de Doutorado, Programa de Pós-Graduação em Psicologia, Universidade Federal do Rio Grande do Sul. Disponível em http: //www.lume.ufrgs.br/handle/10183/16660

Morais, N. A., Paludo, S., \& Koller, S. H. (2010). Famílias de crianças e adolescentes em situação de rua. In N. A. Morais, L. NeivaSilva \& S. H. Koller (Eds.), Endereço desconhecido: crianças e adolescentes em situação de rua (pp. 177-197). São Paulo, Casa do Psicólogo.

Morais, N. A., \& Koller, S. H. (2012). Um estudo com egressos de instituições para crianças em situação de rua: percepção acerca 
da situação atual de vida e do atendimento recebido. Estudos de psicologia (Natal), 17(3), 405-412.

Milburn, N. G., Rosenthal, D., \& Rotheram-Borus, M. J. (2005). Needed: services research with homeless young people. Journal of Health \& Social Policy, 20(3), 1-9.

Paludo, S. S. \& Koller, S. H. (2008). Toda Criança tem família: criança em situação de rua também. Psicologia \& Sociedade, 20(1), 42-52.

Santana, J. P., Doninelli, T. M., Frosi R. V., \& Koller, S. H. (2004). Instituições de atendimento a crianças e adolescentes em situação de rua. Psicologia \& Sociedade, 16(2), 59-70.

Siqueira, A. C. (2012). A garantia ao direito à convivência familiar e comunitária em foco. Estudos de Psicologia, 29(3), 437-444.

Siqueira A. C., \& Dell'Aglio, D. D. (2007). Retornando para a família de origem: fatores de risco e proteção no processo de reinserção de uma adolescente institucionalizada. Revista Brasileira de Crescimento e Desenvolvimento Humano, 17(3), 134-14.

Siqueira, A. C., \& Dell'Aglio, D. D. (2010). Crianças e Adolescentes Institucionalizados: Desempenho Escolar, Satisfação de Vida e Rede de Apoio Social. Psicologia: Teoria e Pesquisa, 26(3), 407415.

Siqueira, A. C., \& Dell'Aglio, D. D. (2011). Políticas públicas de garantia do direito à convivência familiar e comunitária. Psicologia \& Sociedade, 23(2), 262-271.

Siqueira, A. C., Massignan, L. T., \& Dell'Aglio, D. D. (2011). Reinserção familiar de adolescentes: Processos malsucedidos. Paidéia, 21(50), 383-391.

Siqueira, A. C., Morais, N. A., Dell' Aglio, D. D., \& Koller, S. H. (2010). Experiência das casas lares: uma alternativa possível para crianças e adolescentes em situação de rua. In: N. A. Morais, L. Neiva-Silva \& S. H. Koller (Orgs.), Endereço Desconhecido: crianças e adolescentes em situação de rua (pp. 499-529). São Paulo: Casa do Psicólogo.

Yunes, M. A. M., Arrieche, M. R. O., Tavares, M. F. A. \& Faria, L. C. (2001). Família vivida e pensada na percepção de crianças em situação de rua. Paidéia, 11(21), 47-56.

\section{Endereço para correspondência}

\section{Sara Guerra Carvalho de Almeida}

Universidade de Fortaleza

Avenida Washington Soares, 1321, Edson Queiroz, CEP 60811-905, Fortaleza - CE, Brasil

Endereço eletrônico: sarawar@gmail.com

Normanda Araujo de Morais

Universidade de Fortaleza 
Avenida Washington Soares, 1321, Edson Queiroz, CEP 60811-905, Fortaleza - CE, Brasil

Endereço eletrônico: normandaaraujo@gmail.com

Recebido em: 10/03/2015

Reformulado em: 05/03/2016

Aceito para publicação em: 30/03/2016

\section{Notas}

* Mestre e doutoranda em Psicologia pela Universidade de Fortaleza (UNIFOR). Integrante do Laboratório de Estudos dos Sistemas Complexos: casais, família e comunidade (Lesplexos).

** Docente do Programa de Pós-Graduação em Psicologia da Universidade de Fortaleza (UNIFOR). Coordenadora do Lesplexos. Bolsista de Produtividade II do CNPq. 